${ }^{1}$ Department of Biostatistics and Translational Medicine, Medical University of Lodz, Lodz, Poland

2Department of Pediatrics, Oncology and Hematology, Medical University of Lodz, Lodz, Poland

${ }^{3}$ Department of Pediatrics, Diabetology, Endocrinology and Nephrology, Medical University of Lodz, Lodz, Poland

${ }^{4}$ Department of Radiation Oncology, Dana-Farber Cancer Institute, Boston, MA, USA

\title{
Changes in hematological parameters during first days of diabetic ketoacidosis treatment in children with type 1 diabetes mellitus
}

\section{ABSTRACT}

Background. Diabetic ketoacidosis (DKA) is a life-threatening complication of newly diagnosed type 1 diabetes (T1DM) and is associated with severe dehydration.

The aim of the study was to evaluate the changes in hematological parameters (RBC, Hct, Hb, MCV, PLT, WBC) and their correlations with acidosis level and dehydration during ketoacidosis treatment.

Methods. The study group consisted of 262 children with newly diagnosed type 1 diabetes. Clinical data were collected from hospital discharge charts. Data considering hematological parameters were collected from two timepoints: first at admission and second up to 6 days since admission.

Results. Ketoacidosis was present in 76 patients (29.01\%). The DKA group had significantly higher values of baseline RBC ( $p=0.0026)$, Hct $(p=0.0019)$, Hb ( $p=0.0235)$, PLT ( $p=0.0427)$ and WBC count ( $p<0.0001$ ) vs. patients without DKA. Interestingly, baseline MCV level was similar between the groups ( $p=0.9869$ ). During the first days of diabetes treatment, all hematological parameters such as RBC,

Address for correspondence: dr n. med. Wojciech Fendler

Department of Biostatistics and Translational Medicine Medical University of Lodz

e-mail: wojciech.fendler@umed.lodz.pl

Clinical Diabetology 2020, 9, 3, 149-160

DOI: $10.5603 /$ DK.2020.0006

Received: 3.10.2019

Accepted: 26.12.2019
Hct, Hb, PLT and WBC significantly decreased in both groups (all $p$ values $<0.0001$ ), while MCV significantly increased after treatment $(p<0.0001)$. However, the latter was evident only in no-DKA group. Changes in all hematological parameters correlated positively with $\mathrm{pH}$ (all $\mathrm{R}>0.3$ and all $\mathrm{p}$ values $<0.05$ ) in DKA group but not in no-DKA group. However, weak, positive correlations at the margin of statistical significance with $\mathrm{pH}$ were observed for changes in PLT $(p=0.0609)$ and WBC ( $p=0.0811)$ in no-DKA group.

Conclusion. Monitoring dynamics of hematological parameters at T1DM diagnosis may be useful in estimating patients' hydration status. (Clin Diabetol 2020; 9; 3: 149-160)

Key words: type 1 diabetes mellitus, diabetic ketoacidosis, dehydration, blood cell count, fluid therapy

\section{Introduction}

Diabetes mellitus refers to a group of metabolic disorders which are characterized by high glucose concentration resulting from lack of or deficiency in insulin secretion, action or both. In children and adolescents with diabetes, type 1 diabetes (T1DM) is the one most often diagnosed with its underlying cause being autoimmune pancreatic $\beta$-cell destruction leading to insulin deficiency [1]. The prevalence of diabetes is dramatically rising, with the projected number of 
patients estimated to increase by $54 \%$ from 2017 to 2045 to a staggering 693 million [2]. At the same time the incidence of childhood T1DM increases 3\% per year worldwide [2]. Insulinopenia in patients with type 1 diabetes quickly leads to diabetic ketoacidosis (DKA). In this condition insulin deficiency is accompanied by a surge of counterregulatory hormones (glucagon, cortisol, catecholamines and growth hormone), which leads to hyperglycemia, increased lipolysis and ketogenesis. Dehydration sets in soon after, due to glycosuria further aggravated by concomitant vomiting [3]. Eventually, DKA leads to cerebral edema, coma or even death [4-6]. Mild to moderate dehydration in DKA may be managed predominantly by oral rehydration therapy (ORT), which may be bolstered by intravenous (IV) fluid administration in more severe cases, aiming to replenish fluid deficiency over 24 to 48 hours [6]. Cerebral edema is the most severe complication of excessive or too rapid fluid administration. This complication occurs in approximately $0.5 \%$ to $0.9 \%$ of children with newly onset T1DM and concomitant DKA with mortality rate of cerebral edema reaching $24 \%$ [6]. Therefore it is crucial to accurately estimate the degree of dehydration before initiating fluid therapy in DKA. This is not an easy estimate to make though, as dehydration is not directly correlated with the severity of DKA assessed by blood gas values [7].

One of the method used to estimate volume depletion is the Clinical Dehydration Scale (CDS) which takes into consideration: general appearance, sunken eyes, moisture of mucous membranes and tears production. This is a simple and noninvasive indicator but the accuracy of this scale is limited due to the present subjectivity of the performers [8]. Body weight changes during water depletion are also indicative for the degree of dehydration, but given the severity of DKA it is unfeasible in guiding therapy [7]. Moreover, the restitution of initial weight during DKA treatment is also linked to renutrition and insulin administration. Therefore, alternative means are developed to non-invasively, and rapidly evaluate fluid deficiency or overload. One such tool was recently described by Colucci et al. [9]. Their sensor uses nuclear magnetic resonance (NMR) to identify fluid overload in patients with end-stage renal disease (ESRD) at their bedside. Clearly, similar devices may be soon implemented to asses hydration status in children with DKA.

Laboratory measurements are helpful in evaluating hydration in an invasive manner. Plasma osmolality is the most direct test for dehydration, with $300 \mathrm{mOsm} / \mathrm{kg}$ being the commonly accepted threshold for dehydration [10]. However, among patients with DKA, equation for plasma osmolality may underestimate patient's osmolality leading to phenomenon known as osmolal gap (difference between calculated and directly measured osmolality) [11].

Serum sodium concentration alone is also used to estimate extracellular fluid (ECF) volume. However, apart from initial measurement, sodium concentration loses its usefulness during treatment. As plasma glucose concentration decreases due to insulin action, serum sodium concentration increases [12]. Therefore, in DKA one has to rely on corrected sodium concentration or bolster it with blood urea nitrogen measurements as described by Ugale et al. [7].

An alternative approach to estimate the extent of dehydration is the use of blood cell count parameters. Hematocrit $(\mathrm{Hct})$ and hemoglobin $(\mathrm{Hb})$ concentration are two such examples [13, 14]. However hemoglobin measurement is believed to be more verifiable indication of hydration status than hematocrit [15]. Dehydration is also reflected by decreased mean corpuscular volume (MCV) of erythrocytes, elevated platelet (PLT) and white blood cell (WBC) counts but all these attributes are influenced by a variety of other clinical factors [16].

Given this data it seems reasonable that hematological parameters such as increased hematocrit, hemoglobin concentration or platelet count might be useful indicators of deficit in extracellular fluid volume in children with DKA, despite their limitations $[6,12]$. The benefit of this approach is the serial character of blood cell count parameters, routinely measured several times during DKA treatment. This in turn allows to estimate the baseline values for each patient, i.e. those preceding the onset of DKA, and guide fluid replenishment therapy using this data.

Therefore we aimed in this study to evaluate the changes in hematological parameters (RBC [red blood cells], Hct, Hb, MCV, PLT, WBC) and their correlations with acidosis level and dehydration during ketoacidosis treatment.

\section{Methods}

\section{Data collection}

All parents gave their informed consent to use their children's medical documentation for clinical studies. Clinical data from hospital discharge charts were obtained from patients hospitalized in the Department of Pediatrics, Oncology, Hematology and Diabetology of the Medical University of Lodz (currently Department of Pediatrics, Diabetology, Endocrinology and Nephrology) between 2009-2015. In our analysis we included patients with age under 18 and newly diagnosed T1DM. DKA and its severity at onset were assessed by using the International Society for Pediatric and Adolescent 
Diabetes [6] consensus guidelines (mild: venous $\mathrm{pH}$ $<7.3$ or serum bicarbonate concentration $<15$ $\mathrm{mmol} / \mathrm{L}$; moderate: $\mathrm{pH}<7.2$ or serum bicarbonate concentration $<10 \mathrm{mmol} / \mathrm{L}$; severe: $\mathrm{pH}<7.1$ or serum bicarbonate concentration $<5 \mathrm{mmol} / \mathrm{L}$ ). We collected clinical data at T1DM diagnosis about: sex, date of birth, date of diagnosis, diabetes parameters (glucose concentration, $\mathrm{HbA}_{1 c^{\prime}}$ C-peptide, daily dose of insulin per kilogram of body weight (DDI), insulin therapy mode, presence of ICA and anti-GAD antibodies), ketosis parameters $\left(\mathrm{pH}, \mathrm{HCO}_{3}^{-}, \mathrm{BE}\right)$, renal profile (urea, creatinine, urine specific gravity), sodium $\left(\mathrm{Na}^{+}\right)$and potassium $\left(\mathrm{K}^{+}\right)$concentrations, CRP level and hematological parameters (RBC, Hct, Hb, MCV, PLT, WBC). Data considering hematological parameters were collected from two timepoints: first at admission and second up to 6 days since admission. Second measurement was considered as baseline value for each parameter before the DKA onset. Thus, changes of hematological parameters, calculated as a difference between second measurement minus first measurement, may reflect changes in water depletion. We could not provide ketone bodies concentration due to the fact that during diabetes onset they were not routinely examined. Effective osmolality [mOsm $/ \mathrm{kg}$ ] was calculated from following formula [17]: $2\left[\mathrm{Na}^{+}\right]+$glucose/18. As acidosis increases the serum potassium concentration independently of intracellular potassium changes, for every 0.1 unit change of extracellular $\mathrm{pH}$, there is an average $0.6 \mathrm{mEq} / \mathrm{L}$ inverse change of the serum potassium concentration [18]. Thus, following corrected [ $\mathrm{K}^{+}$] $[\mathrm{mEq} / \mathrm{L}]$ formula was used for $\mathrm{pH}<7.35$ : serum potassium + ((pH - 7.35)*0.6*10). eGFR $\left[\mathrm{mL} / \mathrm{min} / 1.73 \mathrm{~m}^{2}\right]$ was calculated using the Schwartz formula [19]: 0.413* (height/serum creatinine). Estimated dehydration [\%] was calculated from multivariate analysis model of measured dehydration provided by Ugale et al. [7]. Formula was as follow: $-22.60+(0.16 * 0.357 *$ urea at admission $)+(0.18$ *sodium concentration at admission).

\section{Data analysis}

Continuous data were presented as median with interquartile range and categorical data were presented as number with respective percentage. For comparison of continuous variables, we used Mann-Whitney $U$ test and categorical data between two groups were compared with Chi-square, Yates correction and Fisher exact test, respectively. Wilcoxon signed-rank test was used to compare changes in hematological parameters after treatment of diabetic ketoacidosis. Spearman rang correlation coefficients were utilized for analysis of correlation. We used multivariate linear regression models for analysis of factors affecting changes in hematological parameters. In order to select variables entering multivariable linear model building for each hematological parameter, from Table 1. We firstly selected variables with $p<0.15$ for correlation in DKA group with each hematological parameter. Afterwards, we checked collinearity of selected variables and excluded one of the variables (with lower $\mathrm{R}$ for correlation with outcome) from highly correlated pair $(R>0.4)$. The final model for each hematological parameter changes was adjusted to age and sex and contained variables with $p<0.15$ in multivariate model. A p-value at the level of $<0.05$ was considered as statistically significant for remaining analysis. All statistical analysis was performed with STATISTICA 13.1 software (TIBCO Palo Alto, CA, USA).

\section{Results}

\section{Study group characteristics}

Among 400 young patients (age $<18$ ) diagnosed with new onset of T1DM between October 2009 and October 2015, we excluded 138 (34.5\%) patients without two results of blood tests meeting predefined criteria. Characteristics of the remaining study group were shown in Table 1. DKA was present in 76 patients (29.01\%).

The DKA group was characterized by significantly higher values of baseline RBC ( $p=0.0026)$, Hct $(p=0.0019), \mathrm{Hb}(p=0.0235)$, PLT $(p=0.0427)$ and WBC count $(p<0.0001) v s$. patients without DKA. Interestingly, baseline MCV level was similar between the groups $(p=0.9869)$. Children with DKA had also higher glucose concentration, $\mathrm{HbA}_{1 c}$ level at diagnosis, effective osmolality, and lower eGFR than those without DKA ( $p<0.0001,0.0126$, $<0.0001$, $<0.0001$, $<0.0001$ respectively). At the discharged, daily dose of insulin (DDI) was significantly higher in DKA group (Me: $0.79 \mathrm{U} / \mathrm{kg}$ (25-75\%: 0.62-0.97 U/kg) vs. Me: 0.58 U/kg (25-75\%: 0.42-0.78 U/kg) p < 0.0001).

During the first days of diabetes treatment, we observed significant decrease of all hematological parameters (all $p$ values < 0.0001 ) except for MCV which significantly increased after treatment $(p<0.0001)$. For changes in $\mathrm{RBC}, \mathrm{Hct}, \mathrm{Hb}$ concentration and platelets count there was no significant correlation with time between the blood tests measurements and the magnitude of parameters' change (all absolute $R<0.1$ and $p$ values $>0.3$ ). However, the change of MCV correlated positively with time between the blood tests measurements $(R=0.14, p=0.0303)$ while WBC change showed a negative correlation $(R=-0.21$, $p=0.0017)$. There was no significant difference in time between two hematological parameters measurements between DKA and no-DKA patients (Me: 3.0 
Table 1. Study group characteristics at T1DM diagnosis

\begin{tabular}{|c|c|c|c|}
\hline Characteristic & $\begin{array}{c}\text { DKA (N = 76) } \\
N(\%)\end{array}$ & $\begin{array}{c}\text { No-DKA }(\mathrm{N}=186) \\
\mathrm{N}(\%)\end{array}$ & $P$ value \\
\hline \multicolumn{4}{|l|}{ Sex } \\
\hline Males & $41(53.95 \%)$ & $108(58.06 \%)$ & 0.5414 \\
\hline Females & $35(46.05 \%)$ & $78(41.94 \%)$ & \\
\hline \multicolumn{4}{|l|}{ Type of therapy } \\
\hline MDI & $71(93.42 \%)$ & $175(95.11 \%)$ & 0.8055 \\
\hline CSII & $5(6.58 \%)$ & $9(4.89 \%)$ & \\
\hline \multicolumn{4}{|l|}{ The presence of antibodies: } \\
\hline ICA & $36(69.23 \%)$ & $84(70.00 \%)$ & 0.9196 \\
\hline GAD & $40(75.47 \%)$ & $90(74.38 \%)$ & 0.9705 \\
\hline \multicolumn{4}{|l|}{ Severity of DKA } \\
\hline Mild & $30(39.47 \%)$ & NA & NA \\
\hline Moderate & $33(43.42 \%)$ & NA & \\
\hline \multirow[t]{2}{*}{ Severe } & $13(17.11 \%)$ & NA & \\
\hline & Me (25-75\%) & Me (25-75\%) & \\
\hline Age at onset (years) & 9.65(4.37-12.54) & $9.24(6.03-13.50)$ & 0.3033 \\
\hline Glucose concentration [mg/dL] & $517.50(390.64-685.00)$ & $402.33(302.87-550.00)$ & $<0.0001$ \\
\hline $\mathrm{HbA}_{1 \mathrm{c}}(\%)$ & $12.30(11.10-13.85)$ & $11.70(10.00-13.30)$ & 0.0126 \\
\hline C-peptide [ng/mL] & $0.33(0.21-0.52)$ & $0.37(0.21-0.64)$ & 0.3787 \\
\hline $\mathrm{pH}$ & $7.24(7.17-7.30)$ & $7.38(7.36-7.41)$ & $<0.0001$ \\
\hline $\mathrm{HCO}_{3}^{-}[\mathrm{mmol} / \mathrm{L}]$ & $9.15(6.55-12.30)$ & $21.60(19.00-23.05)$ & $<0.0001$ \\
\hline $\mathrm{BE}[\mathrm{mEq} / \mathrm{L}]$ & $-16.85(-21.40$ to -12.70$)$ & $-3.00(-5.50$ to -1.60$)$ & $<0.0001$ \\
\hline Effective osmolality [mOsm/kg] & 300.71 (291.17-309.67) & $292.62(288.02-300.62)$ & $<0.0001$ \\
\hline $\mathrm{Na}[\mathrm{mEq} / \mathrm{L}]$ & $135.00(132.00-138.00)$ & $135.00(132.90-137.00)$ & 0.6123 \\
\hline $\mathrm{K}[\mathrm{mEq} / \mathrm{L}]$ & $4.36(4.05-4.90)$ & $4.40(3.98-4.72)$ & 0.2933 \\
\hline Corrected $\mathrm{K}[\mathrm{mEq} / \mathrm{L}]^{*}$ & $3.88(3.02-4.29)$ & $4.37(3.98-4.70)$ & $<0.0001$ \\
\hline Urea [mg/dL] & $27.00(21.40-36.00)$ & $27.91(22.10-34.40)$ & 0.9497 \\
\hline Creatinine $[\mathrm{mg} / \mathrm{dL}]$ & $0.72(0.55-0.95)$ & $0.60(0.49-0.78)$ & 0.0017 \\
\hline eGFR $\left[\mathrm{mL} / \mathrm{min} / 1.73 \mathrm{~m}^{2}\right]$ & 77.47 (63.83-96.05) & 103.25 (88.69-119.55) & $<0.0001$ \\
\hline Urine specific gravity [kg/L] & $1.0225(1.0150-1.0300)$ & $1.0250(1.0150-1.0300)$ & 0.6097 \\
\hline Estimated dehydration (\%) & $3.24(2.54-4.03)$ & $3.27(2.77-3.85)$ & 0.8857 \\
\hline CRP $[\mathrm{mg} / \mathrm{dL}]$ & $0.85(0.20-2.05)$ & $0.30(0.10-1.47)$ & 0.0769 \\
\hline \multicolumn{4}{|l|}{ Before therapy } \\
\hline $\mathrm{RBC}\left[10^{12} / \mathrm{L}\right]$ & $5.15(4.78-5.42)$ & $4.90(4.60-5.23)$ & 0.0026 \\
\hline Hct (\%) & $42.00(39.00-45.50)$ & $40.00(37.20-42.80)$ & 0.0019 \\
\hline $\mathrm{Hb}[\mathrm{g} / \mathrm{dL}]$ & $14.30(13.40-15.50)$ & $13.90(13.20-14.80)$ & 0.0235 \\
\hline $\mathrm{MCV}[\mathrm{fL}]$ & $82.00(79.00-85.00)$ & $82.00(78.00-86.00)$ & 0.9869 \\
\hline PLT $\left[10^{3} / \mu \mathrm{L}\right]$ & $315.00(261.00-354.00)$ & $289.50(240.00-335.00)$ & 0.0427 \\
\hline WBC $\left[10^{3} / \mu \mathrm{L}\right]$ & $13.29(8.50-18.00)$ & $8.79(7.30-10.90)$ & $<0.0001$ \\
\hline \multicolumn{4}{|l|}{ After therapy } \\
\hline $\mathrm{RBC}\left[10^{12} / \mathrm{L}\right]$ & $4.57(4.32-4.90)$ & $4.65(4.38-5.00)$ & 0.1401 \\
\hline Hct (\%) & $37.70(35.65-39.90)$ & $38.20(36.40-41.10)$ & 0.0524 \\
\hline $\mathrm{Hb}[\mathrm{g} / \mathrm{dL}]$ & $12.80(12.20-13.70)$ & $13.20(12.50-14.10)$ & 0.0143 \\
\hline $\mathrm{MCV}[\mathrm{fL}]$ & $82.00(79.00-85.00)$ & $83.00(79.00-87.00)$ & 0.4655 \\
\hline PLT $\left[10^{3} / \mu \mathrm{L}\right]$ & $237.00(188.00-289.00)$ & $255.00(207.00-300.00)$ & 0.0888 \\
\hline WBC $\left[10^{3} / \mu \mathrm{L}\right]$ & $6.70(5.40-8.20)$ & $6.40(5.30-8.30)$ & 0.6946 \\
\hline
\end{tabular}

*Corrected by 0.6 [mEq/L] for every 0.1 unit reduction of $\mathrm{pH} ; \mathrm{MDI}$ - multiple daily insulin injections; CSII - continuous subcutaneous insulin infusion; $\mathrm{DDI}$ - daily dose of insulin; Hct - hematocrit; $\mathrm{Hb}$ - hemoglobin; MCV - means corpuscular volume; PLT — platelets; Me — median; $25-75 \%$ - interquartile range; RBC — red blood cells; WBC — white blood cells 

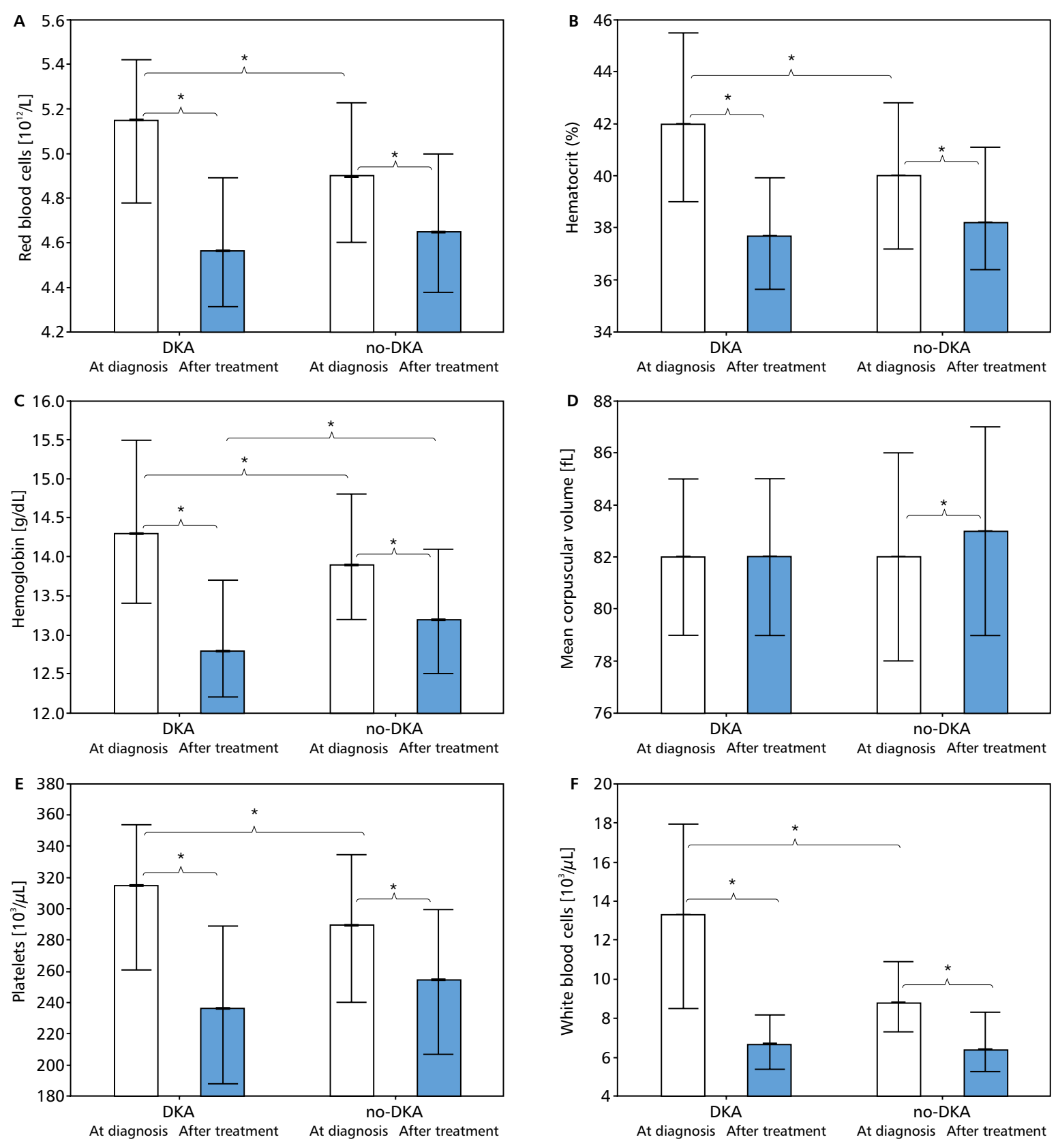

Figure 1. Changes of hematological parameters during first days of newly diagnosed T1DM treatment in children with DKA and without DKA. Red blood cells - A; hematocrit - B; hemoglobin concentration - C; mean corpuscular volume - D; platelets - E; white blood cells - F

days [ $25-75 \%: 2.0-4.0$ days] vs. Me: 3.0 days [ $25-75 \%$ : 2.0-4.0 days] $\mathrm{p}=0.2638$ ).

In general linear models analysis with interaction between group allocation and timepoint there was a significant difference in hematological parameters dynamics change between the groups (all $p$ values $<0.01$ ). Parameters such as RBC, Hct, Hb, PLT and WBC were characterized by greater drop from their baseline values in DKA group vs. non-DKA group (all $p$ values
$<0.0001$ ) (Figure $1 \mathrm{~A}-\mathrm{C}, \mathrm{E}-\mathrm{F}$ ). MCV level increased significantly but only in the no-DKA group $(p<0.0001)$ (Figure 1D).

Correlations between changes in hematological parameters and clinical factors

In order to establish the relationship between patients clinical status at admission with hematological parameters in DKA and no-DKA patients we correlated 
Table 2. Correlations between blood cell parameters at admission of newly diagnosed type 1 diabetes treatment and clinical parameters

\begin{tabular}{|c|c|c|c|c|c|c|c|c|c|c|}
\hline \multirow[b]{2}{*}{ DKA } & \multicolumn{2}{|c|}{$\mathrm{pH}$} & \multicolumn{2}{|c|}{$\begin{array}{l}\text { Effective osmolality } \\
\qquad[\mathrm{mOsm} / \mathrm{kg}]\end{array}$} & \multicolumn{2}{|c|}{$\begin{array}{c}\text { Estimated dehydration } \\
\text { (based on } \mathrm{Na}+\text { and } \\
\text { urea) (\%) }\end{array}$} & \multicolumn{2}{|c|}{$\begin{array}{l}\text { eGFR }[\mathrm{mL} / \mathrm{min} / \\
\left./ 1.73 \mathrm{~m}^{2}\right]\end{array}$} & \multicolumn{2}{|c|}{$\begin{array}{l}\text { C-peptide } \\
{[\mathrm{ng} / \mathrm{mL}]}\end{array}$} \\
\hline & $\mathbf{R}$ & P value & $\mathbf{R}$ & $P$ value & $\mathbf{R}$ & P value & $\mathbf{R}$ & $P$ value & $\mathbf{R}$ & $P$ value \\
\hline $\mathrm{RBC}\left[10^{12} / \mathrm{L}\right]$ & -0.39 & 0.0006 & 0.31 & 0.0076 & 0.34 & 0.0030 & -0.36 & 0.0221 & 0.28 & 0.0246 \\
\hline Hct (\%) & -0.36 & 0.0014 & 0.35 & 0.0022 & 0.32 & 0.0070 & -0.43 & 0.0046 & 0.36 & 0.0041 \\
\hline $\mathrm{Hb}[\mathrm{g} / \mathrm{dL}]$ & -0.42 & 0.0002 & 0.50 & $<0.0001$ & 0.43 & 0.0002 & -0.51 & 0.0006 & 0.43 & 0.0005 \\
\hline MCV [fL] & -0.06 & 0.6327 & 0.13 & 0.2734 & -0.02 & 0.8392 & -0.07 & 0.6677 & 0.25 & 0.0517 \\
\hline PLT $\left[10^{3} / \mu \mathrm{L}\right]$ & 0.03 & 0.8247 & 0.13 & 0.2866 & 0.05 & 0.6780 & -0.15 & 0.3338 & 0.15 & 0.2484 \\
\hline WBC $\left[10^{3} / \mu \mathrm{L}\right]$ & -0.53 & $<0.0001$ & 0.28 & 0.0155 & 0.23 & 0.0560 & -0.44 & 0.0042 & 0.01 & 0.9119 \\
\hline No-DKA & $\mathbf{R}$ & P value & $\mathbf{R}$ & P value & $\mathbf{R}$ & P value & $\mathbf{R}$ & $P$ value & $\mathbf{R}$ & $P$ value \\
\hline $\mathrm{RBC}\left[10^{12} / \mathrm{L}\right]$ & 0.01 & 0.9397 & 0.02 & 0.8300 & 0.09 & 0.2378 & -0.23 & 0.0289 & 0.18 & 0.0255 \\
\hline Hct (\%) & -0.09 & 0.2309 & $<0.01$ & 0.9996 & 0.01 & 0.8922 & -0.05 & 0.6385 & 0.25 & 0.0023 \\
\hline $\mathrm{Hb}[\mathrm{g} / \mathrm{dL}]$ & -0.10 & 0.2089 & 0.12 & 0.1256 & 0.20 & 0.0115 & -0.12 & 0.2620 & 0.21 & 0.0093 \\
\hline $\mathrm{MCV}[\mathrm{fL}]$ & -0.11 & 0.1343 & -0.05 & 0.5197 & -0.16 & 0.0337 & 0.22 & 0.0301 & 0.12 & 0.1415 \\
\hline PLT $\left[10^{3} / \mu \mathrm{L}\right]$ & -0.06 & 0.4582 & -0.08 & 0.3002 & 0.11 & 0.1682 & -0.11 & 0.3090 & -0.19 & 0.0204 \\
\hline WBC $\left[10^{3} / \mu \mathrm{L}\right]$ & -0.19 & 0.0122 & 0.02 & 0.8032 & 0.05 & 0.4991 & -0.21 & 0.0452 & -0.25 & 0.0019 \\
\hline
\end{tabular}

Table 3. Correlations between magnitude of blood cell parameters changes during first days of newly diagnosed type 1 diabetes treatment and clinical parameters

\begin{tabular}{|c|c|c|c|c|c|c|c|c|c|c|}
\hline \multirow[b]{2}{*}{ DKA } & \multicolumn{2}{|c|}{$\mathrm{pH}$} & \multicolumn{2}{|c|}{$\begin{array}{l}\text { Effective osmolality } \\
{[\mathrm{mOsm} / \mathrm{kg}]}\end{array}$} & \multicolumn{2}{|c|}{$\begin{array}{c}\text { Estimated dehydration } \\
\text { (based on } \mathrm{Na}+\text { and } \\
\text { urea) (\%) }\end{array}$} & \multicolumn{2}{|c|}{$\begin{array}{l}\text { eGFR }[\mathrm{mL} / \mathrm{min} / \\
\left./ 1.73 \mathrm{~m}^{2}\right]\end{array}$} & \multicolumn{2}{|c|}{ C-peptide $[\mathrm{ng} / \mathrm{mL}]$} \\
\hline & $\mathbf{R}$ & P value & $\mathbf{R}$ & $P$ value & $\mathbf{R}$ & $P$ value & $\mathbf{R}$ & $P$ value & $\mathbf{R}$ & $P$ value \\
\hline Delta RBC $\left[10^{12} / \mathrm{L}\right]$ & 0.45 & 0.0001 & -0.21 & 0.0847 & -0.19 & 0.1295 & 0.20 & 0.2113 & -0.34 & 0.0084 \\
\hline Delta Hct (\%) & 0.45 & 0.0001 & -0.26 & 0.0284 & -0.23 & 0.0648 & 0.28 & 0.0737 & -0.35 & 0.0067 \\
\hline Delta Hb [g/dL] & 0.45 & 0.0001 & -0.21 & 0.0847 & -0.19 & 0.1295 & 0.20 & 0.2113 & -0.34 & 0.0084 \\
\hline Delta MCV [fL] & 0.30 & 0.0111 & -0.32 & 0.0075 & -0.28 & 0.0220 & 0.49 & 0.0012 & -0.11 & 0.4053 \\
\hline Delta PLT $\left[10^{3} / \mu \mathrm{L}\right]$ & 0.30 & 0.0136 & -0.31 & 0.0113 & -0.21 & 0.0840 & 0.37 & 0.0183 & -0.25 & 0.0535 \\
\hline Delta WBC $\left[10^{3} / \mu \mathrm{L}\right]$ & 0.59 & $<0001$ & -0.25 & 0.0354 & -0.13 & 0.2804 & 0.47 & 0.0022 & -0.08 & 0.5421 \\
\hline No-DKA & $\mathbf{R}$ & $P$ value & $\mathbf{R}$ & $P$ value & $\mathbf{R}$ & $P$ value & $\mathbf{R}$ & $P$ value & $\mathbf{R}$ & $P$ value \\
\hline Delta RBC $\left[10^{12} / \mathrm{L}\right]$ & 0.02 & 0.8355 & -0.04 & 0.6014 & -0.03 & 0.7535 & 0.16 & 0.1355 & 0.07 & 0.4414 \\
\hline Delta Hct (\%) & 0.05 & 0.5712 & 0.04 & 0.5888 & 0.04 & 0.6666 & 0.08 & 0.4344 & 0.10 & 0.2502 \\
\hline Delta $\mathrm{Hb}[\mathrm{g} / \mathrm{dL}]$ & 0.03 & 0.7131 & -0.05 & 0.5147 & -0.03 & 0.6878 & 0.14 & 0.1831 & 0.08 & 0.3522 \\
\hline Delta MCV [fL] & -0.06 & 0.4575 & 0.16 & 0.0536 & 0.19 & 0.0206 & -0.06 & 0.5489 & 0.01 & 0.8633 \\
\hline Delta PLT $\left[10^{3} / \mu \mathrm{L}\right]$ & 0.15 & 0.0609 & $<0.01$ & 0.9955 & -0.02 & 0.7760 & 0.27 & 0.0101 & 0.15 & 0.8633 \\
\hline Delta WBC $\left[10^{3} / \mu \mathrm{L}\right]$ & 0.14 & 0.0811 & -0.13 & 0.0981 & -0.16 & 0.0555 & 0.18 & 0.0841 & -0.05 & 0.5769 \\
\hline
\end{tabular}

them with $\mathrm{pH}$, effective osmolality, estimated dehydration, eGFR and C-peptide (Tables 2 and 3 ) and with age, $\mathrm{HCO}_{3}^{-}, \mathrm{BE}$, time between the blood tests results, urine specific gravity and DDI (Tables S1 and S2).

Firstly, we correlated clinical data with hematological parameters at admission (Tables 2 and S1). $\mathrm{RBC}, \mathrm{Hct}$ and $\mathrm{Hb}$ in DKA group correlated significantly, negatively with $\mathrm{pH}$ and eGFR and positively with effective osmolality, estimated dehydration and C-peptide. Among those, only correlation between C-peptide with $\mathrm{RBC}$, Hct and $\mathrm{Hb}$ were significant also in no-DKA group. WBC correlated negatively and significant with $\mathrm{pH}$ and eGFR in both groups. Relationships between $\mathrm{BE}$ and hematological parameters at admission (Table S1) 


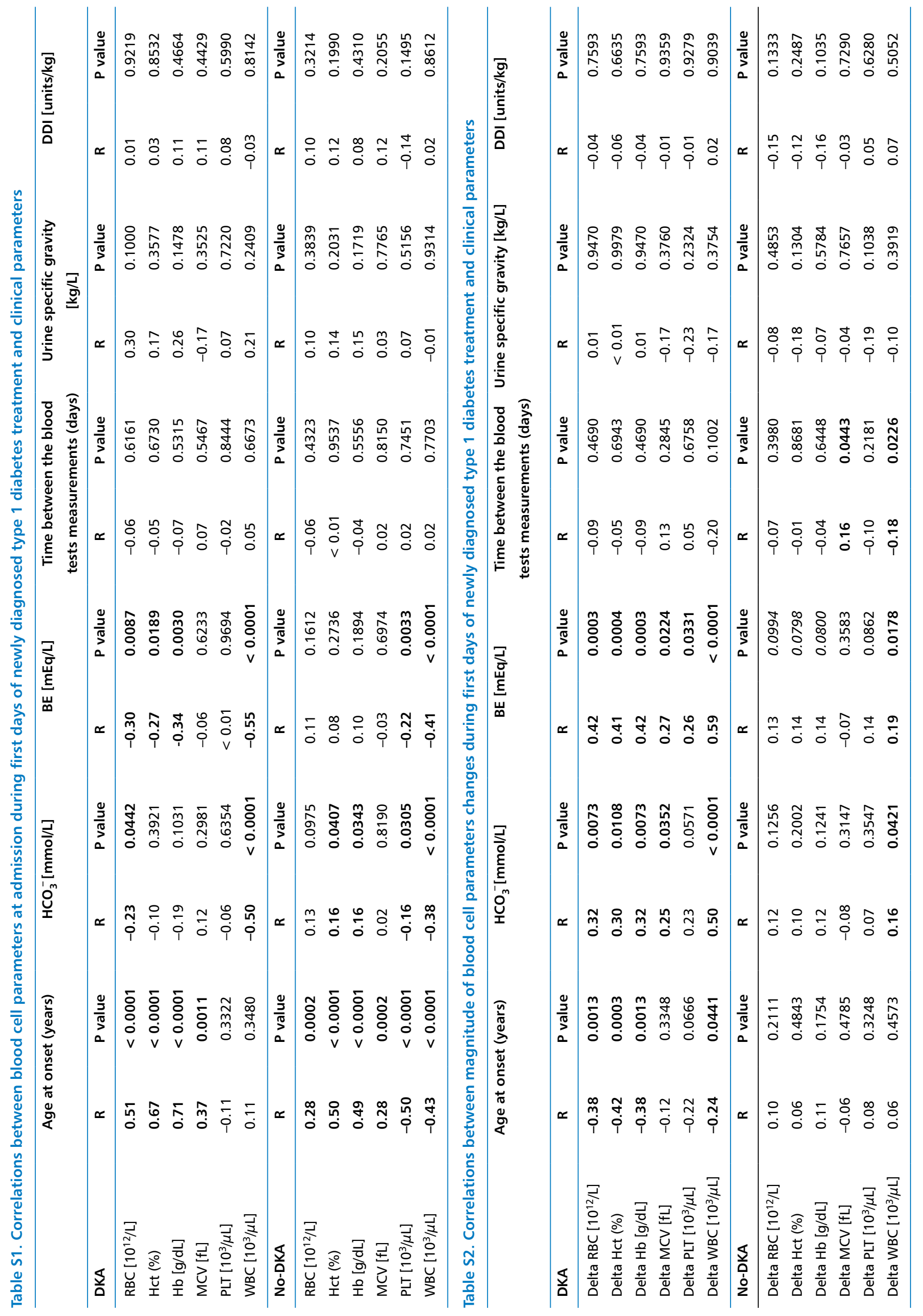



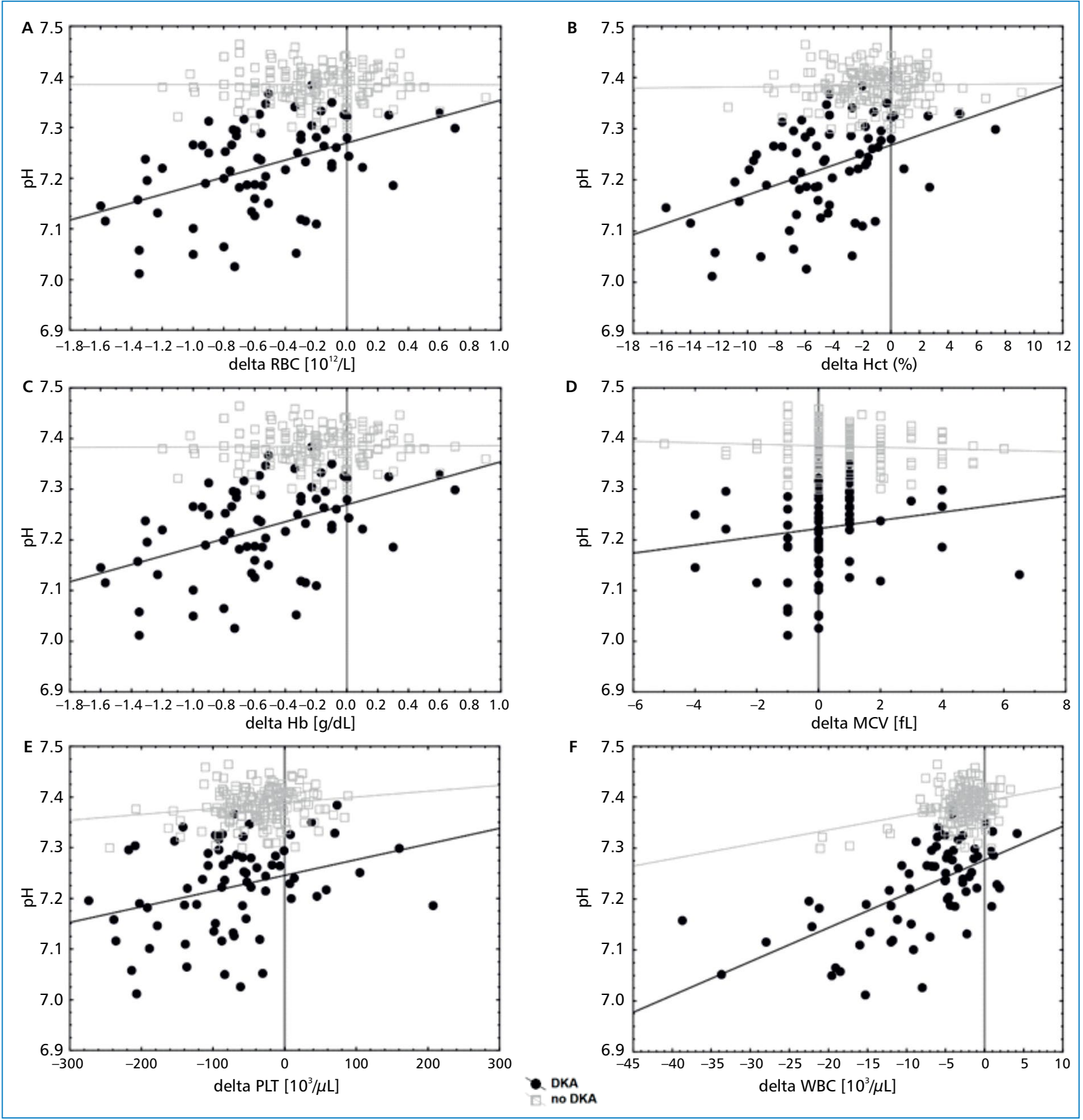

Figure 2. Correlations between $\mathrm{pH}$ and changes in morphological parameters during first days of newly diagnosed T1DM treatment in children with DKA and without DKA. RBC (red blood cells) - A; Hct (hematocrit) - B; Hb (hemoglobin) - C; MCV (mean corpuscular volume) - D; PLT (platelets) - E; WBC (white blood cells) - F

showed similar dynamics as correlations with $\mathrm{pH}$ in the DKA group. For $\mathrm{HCO}_{3}^{-}$only correlations with $\mathrm{RBC}$ and WBC were significant. Interestingly, in no-DKA group significant and negative correlations between PLT and both $\mathrm{BE}$ and $\mathrm{HCO}_{3}^{-}$, were observed. Additionally, also only in no-DKA group significant and positive correlations between $\mathrm{HCO}_{3}^{-}$with $\mathrm{Hct}$ and $\mathrm{Hb}$ were observed.

After that, we correlated patients' clinical status with changes in hematological parameters since admission (Tables 3 and S2). In the DKA group changes in all hematological parameters correlated positively with $\mathrm{pH}$ (all $\mathrm{R}>0.3$ and all $\mathrm{p}$ values $<0.05$ ) (Figure 2). Relationships in the DKA group between changes in hematological parameters and both $\mathrm{HCO}_{3}^{-}$(Table S2) and base excess (Table S2), showed similar dynamics to $\mathrm{pH}$. In comparison, in the no-DKA group which was 2.5-times more numerous than DKA group, no correlations with $\mathrm{pH}$ were noted for changes in RBC, $\mathrm{Hct}, \mathrm{Hb}$ and MCV. However, for change in PLT and WBC weak, positive correlations with $\mathrm{pH}$ at the margin of 
statistical significance were noted. For correlations with $\mathrm{HCO}_{3}^{-}$and base excess, no significant associations with hematological parameters changes were found in the no-DKA group, except for WBC and both $\mathrm{HCO}_{3}^{-}$and $\mathrm{BE}$ (Table S2) and weak positive correlations at the margin of statistical significance of $\mathrm{BE}$ and changes in RBC, $\mathrm{Hct}, \mathrm{Hb}$ and PLT.

Effective plasma osmolality significantly, negatively correlated with all hematological changes but only in DKA group (delta RBC and delta $\mathrm{Hb}$ were at the margin of statistical significance). Dehydration estimated by equation provided by Ugale et al. [7] correlated negatively (with borderline significance) with all hematological changes but also only in DKA group. Strangely, the change of MCV correlated significantly but negatively with estimated dehydration in DKA group but significantly and positively in no-DKA group. eGFR correlated strongly positively with the changes of MCV and WBC in DKA group and with the change of PLT both in DKA and no-DKA group. C-peptide correlated significantly and negatively with changes in $\mathrm{RBC}$, Hct and $\mathrm{Hb}$ only in DKA group and at the borderline significance with the PLT change.

When correlation between each change in hematological parameters were performed, all but MCV, changes significantly, positively correlated with each other (all $R>0.4$, all $p$ values $<0.0001)$. The change of MCV correlated only with the change of $\mathrm{Hct}(R=0.21$, $\mathrm{p}=0.0017)$.

\section{Multivariate models explaining changes in} hematological parameters during DKA treatment

In order to evaluate which clinical variables can explain changes of hematological parameters in DKA group, we performed multivariate analyses (Tables S3). The change of $\mathrm{RBC}$ and $\mathrm{Hb}$ were both independently positively associated with $\mathrm{pH}$ and negatively with C-peptide. Similar associations were found in the multivariate model for change in Hct which additionally showed significant negative association with creatinine concentration. For the change of RBC, Hct and $\mathrm{Hb}$ built models explained more than $30 \%$ of parameter variation (adjusted $\mathrm{R}^{2}$ ).

The change of MCV was significantly and negatively associated with glucose concentration. Our model explained only $7 \%$ of parameter variance suggesting that other variable (not included in our database) are associated with MCV changes during DKA treatment.

PLT changes was associated positively with $\mathrm{pH}$ and negatively with glucose concentration. The model explained $17.5 \%$ of parameter variation.

For the change of WBC we were able to create model comprising 3 variables: $B E$ (positive association), creatinine level (negative association) and potassium level (negative association). Model explained almost $42 \%$ of changes in WBC variation.

\section{Discussion}

In this study we found that hematological parameters such as RBC, Hct, Hb, PLT and WBC decreased after fluid therapy among children with newly diagnosed T1DM. At the diagnosis, abovementioned hematological parameters were higher in DKA group compared to no-DKA group. Also, these parameters had greater magnitude of changes from their baseline values in DKA in comparison to no-DKA group. Interestingly, MCV increased after fluid therapy but only in no-DKA group.

MCV changes may be associated with changing plasma osmolality during fluid therapy. Dehydration may influence MCV but the direction of change depends on plasma osmolality. During hyperosmolar dehydration the plasma volume is decreasing (mainly water), which leads to uneven ion concentration between inside of red blood cells and plasma itself. In order to rebalance the concentration, water is moving from the inside of RBC to the extracellular space. As the consequence, $\mathrm{RBC}$ shrinks and thus $\mathrm{MCV}$ is reduced.

Effective plasma osmolality was higher in DKA group compared to no-DKA group. Hence, odd is the fact that in our study the DKA group had the same MCV values at T1DM diagnosis as no-DKA group. Moreover, in no-DKA group MCV increased significantly after fluid therapy, but this dynamics were not present in DKA group. We believe that the increased MCV may suggests over hydration in patients from no-DKA group. To support this hypothesis, we observed positive correlation of the delta MCV with time between the blood tests measurements suggesting that longer time of fluid therapy is associated with bigger change of MCV. On the other hand, the lack of increase in MCV in DKA group after fluids therapy may suggest improper restoring of plasma osmolality after treatment.

Decreased MCV may also result from iron or copper deficiency and different types of hemoglobinopathies [20]. MCV may increase due to the anemia, vitamin B12 or folate deficiency, alcohol abuse and many other disorders [21]. However, due to short period of time between blood test measurements, we can assume that those factors did not affect MCV in our studies.

Other hematological parameters (RBC, Hct, $\mathrm{Hb}$, PLT and WBC) had the same dynamics of change in both DKA and no-DKA group, but greater magnitude of changes were observed in DKA group. It could suggest that children with DKA were more dehydrated and it was reflected by higher blood condensation at diabetes diagnosis. 
Table S3. Multivariate linear models for changes in RBC, Hct, Hb, MCV, PLT and WBC

\begin{tabular}{|c|c|c|c|c|c|c|c|}
\hline Delta RBC & $\mathbf{R}^{2}$ & $\mathrm{R}^{2} \mathrm{adj}$ & $\begin{array}{l}\text { P value for } \\
\text { the model }\end{array}$ & Delta MCV & $\mathbf{R}^{2}$ & $\mathrm{R}^{2}$ adj. & $\begin{array}{l}P \text { value for } \\
\text { the model }\end{array}$ \\
\hline & $38.91 \%$ & $34.47 \%$ & $<0.0001$ & & $11.18 \%$ & $7.15 \%$ & 0.0484 \\
\hline Variables & Beta & Beta* & P value & Variables & Beta & Beta* & P value \\
\hline Intercept & -16.7650 & & 0.0004 & Intercept & 1.5844 & & 0.0053 \\
\hline Sex - male & -0.0093 & -0.02 & 0.8607 & Sex - male & -0.0886 & -0.05 & 0.6466 \\
\hline Age (years) & -0.0248 & -0.25 & 0.0345 & Age (years) & -0.0190 & -0.06 & 0.6428 \\
\hline $\mathrm{pH}$ & 2.2952 & 0.42 & 0.0004 & $\begin{array}{l}\text { Glucose concentration } \\
{[\mathrm{mg} / \mathrm{dL}]}\end{array}$ & -0.0020 & -0.30 & 0.0145 \\
\hline C-peptide [ng/mL] & -0.3138 & -0.21 & 0.0720 & & & & \\
\hline \multirow[t]{2}{*}{ Delta Hct } & $\mathrm{R}^{2}$ & $\mathrm{R}^{2}$ adj. & $\begin{array}{l}\text { P value for } \\
\text { the model }\end{array}$ & Delta PLT & $\mathrm{R}^{2}$ & $R^{2}$ adj. & $\begin{array}{l}\text { P value for } \\
\text { the model }\end{array}$ \\
\hline & $44.44 \%$ & $39.20 \%$ & $<0.0001$ & & $22.35 \%$ & $17.50 \%$ & 0.0025 \\
\hline Variables & Beta & Beta* & P value & Variables & Beta & Beta* & P value \\
\hline Intercept & -127.4183 & & 0.0027 & Intercept & -1549.9744 & & 0.0883 \\
\hline Sex - male & 0.0433 & 0.01 & 0.9252 & Sex - male & 8.5233 & 0.09 & 0.4130 \\
\hline Age (years) & -0.1601 & -0.18 & 0.1607 & Age (years) & -3.0931 & -0.16 & 0.1659 \\
\hline $\mathrm{pH}$ & 17.6857 & 0.36 & 0.0023 & $\mathrm{pH}$ & 216.9799 & 0.21 & 0.0817 \\
\hline Creatinine $[\mathrm{mg} / \mathrm{dL}]$ & -2.9730 & -0.23 & 0.0897 & $\begin{array}{l}\text { Glucose concentration } \\
{[\mathrm{mg} / \mathrm{dL}]}\end{array}$ & -0.1094 & -0.29 & 0.0162 \\
\hline C-peptide [ng/mL] & -2.7970 & -0.20 & 0.0661 & & & & \\
\hline \multirow[t]{2}{*}{ Delta $\mathrm{Hb}$} & $\mathbf{R}^{2}$ & $\mathrm{R}^{2} \mathrm{adj}$ & $\begin{array}{l}\text { P value for } \\
\text { the model }\end{array}$ & Delta WBC & $\mathbf{R}^{2}$ & $\mathrm{R}^{2}$ adj. & $\begin{array}{l}P \text { value for } \\
\text { the model }\end{array}$ \\
\hline & $38.91 \%$ & $34.47 \%$ & $<0.0001$ & & $46.26 \%$ & $41.92 \%$ & $<0.0001$ \\
\hline Variables & Beta & Beta* & P value & Variables & Beta & Beta* & $P$ value \\
\hline Intercept & -16.7650 & & 0.0004 & Intercept & 17.1585 & & 0.0021 \\
\hline Sex - male & -0.0093 & -0.02 & 0.8607 & Sex - male & -0.7409 & -0.10 & 0.3040 \\
\hline Age (years) & -0.0248 & -0.25 & 0.0345 & Age (years) & -0.0899 & -0.06 & 0.6173 \\
\hline $\mathrm{pH}$ & 2.2952 & 0.42 & 0.0004 & $\mathrm{BE}[\mathrm{mEq} / \mathrm{L}]$ & 0.7697 & 0.51 & $<0.0001$ \\
\hline \multirow[t]{2}{*}{ C-peptide [ng/mL] } & -0.3138 & -0.21 & 0.0720 & Creatinine $[\mathrm{mg} / \mathrm{dL}]$ & -4.7149 & -0.21 & 0.0931 \\
\hline & & & & $\mathrm{K}[\mathrm{mEq} / \mathrm{L}]$ & -1.6080 & 0.15 & 0.1326 \\
\hline
\end{tabular}

Based on correlations between changes in each hematological parameters (RBC, Hct, Hb, MCV, PLT and WBC) with $\mathrm{pH}$, we assumed that severity of DKA is associated with dehydration expressed as greater change of each parameter from the baseline level. Our findings are not consistent with those provided by Ugale et al. [7]. This difference might arose from fact that they measured dehydration as a change of body mass. Measuring change of body mass as a dehydration status may be affected by e.g. body fat percentage. Thus, when patient has higher percentage of body fat and loses e.g. $10 \%$ of total body water, the change in total body weight will be smaller in comparison to the lean patient with the same percentage of lost total body water. Additionally, renutrition and insulin administration may affect body mass. These might be the reasons of the different results between our study and Ugale's one. Also, estimated dehydration provided in Ugale's study did not differ significantly between DKA and noDKA group in our study. This result is rather strange and we believe that it may indicate that this equation is not accurate in estimating dehydration in newly diagnosed T1DM patients as the difference in hydration status between those two group was shown by lower eGFR and higher effective plasma osmolality in DKA group.

Furthermore, our study showed that only RBC, Hct and $\mathrm{Hb}$ at admission correlated significantly and negatively with eGFR and $\mathrm{pH}$ and positively with estimated dehydration, effective osmolality and C-peptide. This could further support hypothesis that higher RBC, Hct and $\mathrm{Hb}$ at diagnosis and their further drop after fluid administration is strongly associated with patients 
hydration status and could help clinicians to estimate patients hydration status at T1DM diagnosis. However, those correlations were not evident in no-DKA group what could emerge from lesser dehydration in this group of patients (eGFR and plasma osmolality were mostly within normal limits in this group).

Interestingly, even though most of above-mentioned correlations were not present in no-DKA group, positive correlation between C-peptide and RBC, Hct, $\mathrm{Hb}$ was significant in both groups. We presume that higher C-peptide concentration at admission (preserved residual beta-cell function) was associated with longer development of full symptomatic type 1 diabetes that forced patients and their parents to seek medical counselling. Thus, with longer time, those children may develop greater dehydration as shown by lower RBC, $\mathrm{Hct}$ and $\mathrm{Hb}$ without much changes in plasma osmolality and eGFR due to compensatory mechanisms.

Also we observed increased level of PLT count at T1DM diagnosis and higher levels of this parameter in DKA group. Venous thrombosis compilations are rare but well-known consequences of DKA [22]. Increased PLT count may partially explain this phenomenon in addition to already known increased platelet aggregation, elevated levels of procoagulants and decreased activity of anticoagulants in patients with DKA [23]. All of this, could suggest consideration of antithrombotic treatment among patients with DKA and high PLT count.

Despite above-mentioned parameter, also WBC shared the same dynamics of change (significant drop after treatment and higher levels in DKA group at admission). It is known that WBC reflects systemic inflammation level but taking into consideration that most of our patient had CRP levels with normal limits, it suggest that here higher WBC could be also a marker of blood condensation. Interestingly, WBC values most strongly correlated with $\mathrm{pH}$ level in DKA group and this association was also present in no-DKA group and this phenomenon was also observed by others [24].

The main limitation of our study was lack of directly measured dehydration. Thereby, we were not able to associate blood morphology parameters and their changes with true patients' hydration status. Additionally, the amount of administered fluids was not registered and we draw our conclusion on effect of fluid therapy using time between the blood samples collection as a surrogate of administered fluid volume. Also, absence of ketone bodies concentration can be consider as a study limitation. Due to retrospective character of our study we were not able to obtain measurements of this parameter. However taking into consideration that all patients were newly diagnosed with T1DM and improved with insulin therapy we may assume that only diabetic ketoacidosis was an underlying cause of acidosis among those patients. Finally, we used hematological parameter after treatment as baseline values as we were not able to obtain their values shortly before development T1DM. Another solution would be to verify hematological parameters 6 months after hospitalization, but we believe that other factors (e.g. diet) might influenced them in such a long period of time and disturbed the results.

\section{Conclusions}

Hematological parameters measured at T1DM diagnosis may be useful in estimating patients' hydration status. Monitoring of their dynamics during fluid therapy may inform about the treatment effectiveness in restoring total body water.

\section{Acknowledgments}

The study was founded by Diabetes Poland Scientific Grant with BM as its principal investigator.

\section{Statement of competing interests}

The authors have no conflicts of interest to disclose.

\section{REFERENCES}

1. American Diabetes Association/ADA. Diagnosis and classification of diabetes mellitus. American Diabetes Association. Diabetes Care. 2014; 37(Suppl 1): S81-90, doi: 10.2337/dc10-S062.

2. Cho NH, Shaw JE, Karuranga S, et al. IDF Diabetes Atlas: Global estimates of diabetes prevalence for 2017 and projections for 2045. Diabetes Res Clin Pract. 2018; 138: 271-281, doi: 10.1016/j. diabres.2018.02.023, indexed in Pubmed: 29496507.

3. Kitabchi $A E$, Umpierrez GE, Murphy MB, et al. Hyperglycemic crises in adult patients with diabetes: a consensus statement from the American Diabetes Association. Diabetes Care. 2006; 29(12): 2739-2748, doi: 10.2337/dc06-9916, indexed in Pubmed: 17130218.

4. Li W, Huang E, Gao S. Type 1 Diabetes Mellitus and Cognitive Impairments: A Systematic Review. J Alzheimers Dis. 2017; 57(1): 29-36, doi: 10.3233/JAD-161250, indexed in Pubmed: 28222533.

5. Edge JA, Ford-Adams ME, Dunger DB. Causes of death in children with insulin dependent diabetes 1990-96. Arch Dis Child. 1999; 81(4): 318-323, doi: 10.1136/adc.81.4.318, indexed in Pubmed: 10490436.

6. Wolfsdorf Jl, Glaser N, Agus M, et al. ISPAD Clinical Practice Consensus Guidelines 2018: Diabetic ketoacidosis and the hyperglycemic hyperosmolar state. Pediatr Diabetes. 2018; 19 Suppl 27: 155-177, doi: 10.1111/pedi.12701, indexed in Pubmed: 29900641.

7. Ugale J, Mata A, Meert KL, et al. Measured degree of dehydration in children and adolescents with type 1 diabetic ketoacidosis. Pediatr Crit Care Med. 2012; 13(2): e103-e107, doi: 10.1097/ PCC.0b013e3182231493, indexed in Pubmed: 21666534.

8. Koves IH, Neutze J, Donath S, et al. The accuracy of clinical assessment of dehydration during diabetic ketoacidosis in childhood. Diabetes Care. 2004; 27(10): 2485-2487, doi: 10.2337/ diacare.27.10.2485, indexed in Pubmed: 15451920.

9. Colucci LA, Corapi KM, Li M, et al. Fluid assessment in dialysis patients by point-of-care magnetic relaxometry. Sci Transl Med. 2019; 11(502), doi: 10.1126/scitranslmed.aau1749, indexed in Pubmed: 31341060. 
10. Armstrong LE. Assessing hydration status: the elusive gold standard. J Am Coll Nutr. 2007; 26(5 Suppl): 575S-584S, doi: 10.1080/07315724.2007.10719661, indexed in Pubmed: 17921468.

11. Davidson DF. Excess osmolal gap in diabetic ketoacidosis explained. Clin Chem. 2019; 38(5): 755-757, doi: 10.1093/ clinchem/38.5.755.

12. Wolfsdorf J, Craig ME, Daneman D, et al. Diabetic ketoacidosis in children and adolescents with diabetes. Pediatr Diabetes. 2009; 10 Suppl 12: 118-133, doi: 10.1111/j.1399-5448.2009.00569.x, indexed in Pubmed: 19754623.

13. Bruck $E$. Laboratory tests in the analysis of states of dehydration. Pediatr Clin North Am. 1971; 18(1): 265-283, doi: 10.1016/s00313955(16)32538-x, indexed in Pubmed: 25868190.

14. Hosten AO. Clinical Methods: The History, Physical, and Laboratory Examinations. 3rd edition. In: Clinical Methods, 3rd edition The History, Physical, and Laboratory Examinations. 1990: 718-719.

15. Ritchie RF, Ledue TB, Craig WY. Patient hydration: a major source of laboratory uncertainty. Clin Chem Lab Med. 2007; 45(2): 158-166, doi: 10.1515/CCLM.2007.052, indexed in Pubmed: 17311501.

16. Tefferi A, Hanson CA, Inwards DJ. How to interpret and pursue an abnormal complete blood cell count in adults. Mayo Clin Proc. 2005; 80(7): 923-936, doi: 10.4065/80.7.923, indexed in Pubmed: 16007898

17. Rasouli M. Basic concepts and practical equations on osmolality: Biochemical approach. Clin Biochem. 2016; 49(12): 936-941, doi: 10.1016/j.clinbiochem.2016.06.001, indexed in Pubmed: 27343561.
18. Burnell JM, Scribner BH, Uyeno BT, et al. The effect in humans of extracellular $\mathrm{pH}$ change on the relationship between serum potassium concentration and intracellular potassium. J Clin Invest. 1956; 35(9): 935-939, doi: 10.1172/JCI103352, indexed in Pubmed: 13367188.

19. Schwartz GJ, Work DF. Measurement and estimation of GFR in children and adolescents. Clin J Am Soc Nephrol. 2009; 4(11): 1832-1843, doi: 10.2215/CJN.01640309, indexed in Pubmed: 19820136.

20. Brandow A. Pallor and Anemia. Nelson Pediatric Symptom-Based Diagnosis. 2018: 661-681.e2, doi: 10.1016/b978-0-323-399562.00037-6.

21. Dasgupta A. Mean corpuscular volume and carbohydrate-deficient transferrin as alcohol biomarkers. In: Alcohol and its Biomarkers. 2015: 139-162, doi: 10.1016/b978-0-12-800339-8.00006-7.

22. Bilici M, Tavil B, Dogru O, et al. Diabetic ketoasidosis is associated with prothrombotic tendency in children. Pediatr Hematol Oncol. 2011; 28(5): 418-424, doi: 10.3109/08880018.2011.558568, indexed in Pubmed: 21615248.

23. Foster JR, Morrison G, Fraser DD. Diabetic ketoacidosis-associated stroke in children and youth. Stroke Res Treat. 2011: 219706, doi: 10.4061/2011/219706, indexed in Pubmed: 21423557.

24. Xu W, Wu Hf, Ma Sg, et al. Correlation between peripheral white blood cell counts and hyperglycemic emergencies. Int J Med Sci. 2013; 10(6): 758-765, doi: 10.7150/ijms.6155, indexed in Pubmed: 23630441. 